\title{
Study on the Development Strategy of Ceramic Cultural Creative Industry under the Strategy of "One Belt and One Road" - Taking Jingdezhen as an Example
}

\author{
Dawei Ke \\ Jingdezhen Ceramic Institute, Jingdezhen, Jiangxi 333403, China \\ 370602262@qq.com
}

Keywords: "One Belt and One Road"; Ceramic culture; Creative industry; Development strategy.

\begin{abstract}
The strategy of "One Belt and One Road" is the national strategy put forward by the state in order to promote the common development of the neighboring countries of the Silk Road. The ceramic as a typical Chinese traditional culture carrier, in the strategic background of "One Belt and One Road", is bound to play a more significant in cultural exchanges and heritage. Millennium porcelain city - Jingdezhen, as an important representative place of China's ceramic culture, have great responsibility for constructing ceramic culture and creative industries, promoting its development. Based on the present situation and significance of the development of Jingdezhen ceramic culture and creative industry under the strategy of "One Belt and One Road", this paper carried out analysis according to the strategic layout and problems existing in the current development, and finally puts forward the development suggestions and countermeasures, in order to communicate with each other.

The level of cultural development is an important manifestation of the country's soft power. In recent years, the cultural and creative industries have gradually revealed its role in promoting the world's social and economic development. Partial developed countries are treating the cultural and creative industries as the new forces of leading industry to promote innovation and development and pay more attention to it. Taking the United States as an example, since 1996, the US cultural and creative industries have exceeded other traditional industries, cultural and creative products will become its largest export products, until 2002, the output value brought from the creative industry has accounted for 5.24\% of US GDP [1]. China's first-class cities have also taken the development of cultural and creative industries into the planning, the established cultural and creative industries bases have gradually come to get fruits. Jingdezhen has the inherent advantages of ceramic culture, the development of cultural and creative industries is an inevitable trend. Based on the study of Jingdezhen ceramic culture and creative industry, it is found that there are still some limitations in the current industrial development strategy and the actual operation, carrying out the study of national strategy combining with the current "One Belt and One Road", in order to put forward effective targeted solutions, and promote the further development of Jingdezhen cultural and creative industries.
\end{abstract}

\section{The Introduction of the Current Situation}

"One Belt and One Road" belongs to the international opening strategy, the relevant nodes of the cities should actively use this strategic opportunity to promote economic exchange, industrial cooperation, brand building cooperation of urban representatives and so on[2]. Ceramics as a powerful representative of the world to understand China, thousands of years of continuous forging charm of Jingdezhen make a great contribution. Therefore, the implementation of "One Belt and One Road" strategy and related policies is definitely an important opportunity for the current Jingdezhen ceramic cultural industry development. As an important starting point and intersection of the Silk Road and sea, Jingdezhen ceramic cultural and creative industry development integrating into the "One Belt and One Road" strategic policy, can be described as a unique advantage.

However, in the current development of Jingdezhen ceramic culture industry, incomplete system, lack of creativity and lack of demand and other serious problems are existing, reducing the brand 
influence and market sales ability. How to strengthen the development, optimization and promotion of this creative industry chain, but also need to further integrate the force of "One Belt and One Road" strategic policy, as well as marketing and industrial economics knowledge, commonly help to realize a new chapter of Jingdezhen ceramic culture and creative industry development.

\section{Analysis on the Significance of Research}

Analysis from the Theoretical Aspects. First of all, studying strategy of Jingdezhen ceramic culture and creative industry development is the requirement of the new era of Silk Road tourism development and the "One Belt and One Road" strategy to promote mutual benefit and regional economic development, cultural exchange and study [3]; Secondly, The study of the strategy is the requirement of Jingdezhen ceramic culture itself long-term development. The study of new countermeasures of cultural and creative industries development can help the brand and economic development, and promote the achievement of its sales and greater value; Thirdly, the study of countermeasures is the inevitable requirements of the current people's individual consumption. Inheriting the traditional excellent elements, innovation and development strategies, to be able to meet the innovative pursuit of consumers; Finally, the study has a strong development prospects. To further provide powerful help for promoting the economic, tourism and cultural development, which have been well reflected well from the current experience of the international developed countries.

Analysis from the Practical Aspects. The research problem of this research institute is based on the important problems such as the construction of the city brand in Jingdezhen ceramic culture industry. The exploration of the solution strategy is also aimed at solving these problems. Therefore, it has a very important practical significance for the development of Jingdezhen and maintain the status of their international porcelain city [4].

\section{Strategy Layout and Existing Problems of Jingdezhen Ceramic Culture and Creative Industry Development}

Strategy layout of Jingdezhen Ceramic Culture and Creative Industry Development. Based on the rich practical considerations of ceramics and their cultural resources, Jingdezhen has gradually started to build a strategic layout of ceramic culture and creative industries, and will plan all R \& D production, cultural tourism, exchange consultation and culture creative exhibitions to their respective gathering areas and encourage them to carry out exchanges and cooperation based on the advantages to promote the formation of a comprehensive cultural and creative industry base, laying a solid foundation for system formation and development of Jingdezhen ceramic culture and creative industry.

Existing Problems of Jingdezhen Ceramic Culture and Creative Industry Development. First, there is a lack of demand. The improvement of social material economic level has led to the improvement of people's income and the pursuit of spiritual and cultural needs, which has stimulated the great development of the current creative industries. The demand structure and the total demand are the main reasons for determining the expansion of specific creative industries or sectors. Such that the proportion of the existence of private investment in creative industries become larger, or the increase of government-oriented support policies and funds and so on. However, from the current income, level of consumption, structure and demand of China and the world's people, the overall demand of creative products in Jiangxi, the whole country and the world is still slightly low, the whole consumer market of ceramic culture and creative industries needs to get further cultivation and activation, consumption level also need to be improved.

Secondly, there is a serious phenomenon of old concept and talent imbalance. Since Jingdezhen is not very urgent in the expansion of ceramic culture and creative industries demand, leading to few cooperation between the relevant government policy support, corporate investment with the industry, resulting in that the development of ideas and talent supply can not keep up with the needs. Although the development of ceramic culture has always been an important carrier of Jingdezhen 
traditional regional cultural heritage, but its industry has been relatively slow development in a long period of time, resulting in a serious the lag of upgrade and transformation of creative industry development concept. Therefore, the lag of the concept coupled with the imbalance of talent, so that production scale and influence are limited, bringing serious obstacles to its development.

Third, intellectual property protection is slightly weak. Creativity, to some extent, is a manifestation of wealth and productivity, and intellectual property is its most important way to protect. However, the current development of Jingdezhen ceramic culture and creative industry is still in the initial stage of cultivation, size and influence are insufficient, once the work is imitated or copied then flowed into the market, then the so-called creativity will lose the value and role, but some creators were not aware of the importance of this point, wrongly judged it as conducive to the market activities, did not take the necessary intellectual property protection measures, resulting in the contradiction of the system and benefit in the development.

Finally, the local institutional management barriers, resources can not achieve effective allocation. Although Jingdezhen ceramic culture is rich in resources, but the management is very fragmented, there are obstacles in the system, making the lack of effective allocation of resources and integration mechanism, can not take the advantages and play role of industrial development. For provincial cultural and creative industries supporting policies, less specifically related to the ceramic industry, can not attract the attention of investors well. Besides, because the short-term recovery efficiency is not obvious, resulting in investment in high-tech emerging ceramic industry is even less, companies are more waiting for the situation.

\section{The Specific Countermeasures for the Development of Jingdezhen Ceramic Culture and Creative Industry under the Strategy of "One Belt and One Road"}

Create a Favorable Environment for the Ceramic Culture and Creative Industries. First of all, from the experience of the development of international cultural and creative industries, the current government must create a favorable policy environment for Jingdezhen ceramic culture and creative industries. Second, enhance management and guidance to the cultural market. Increase the comprehensive law enforcement efforts to ensure the maintenance of cultural and intellectual property rights according to law. Through the ceramic culture and creative industry associations and other organizations, to fully stimulate the functions of industry norms, coordination and self-discipline, to promote standardized operation of cultural products, technical transactions, assessment and identification. Finally, strengthen the industry-related basic work plan. Formulate and implement the Jingdezhen ceramic culture and creative industry development planning rules, the investment guidance, policy encouragement, system requirements and other aspects are included in the rules, establish scientific and standardized industrial assessment standards, and enhance market research efforts to develop a scientific $\mathrm{R} \& \mathrm{D}$ production program , to stimulate the growth of consumer demand.

Provide Policy Support for the Ceramic Culture and Creative Industries. In the context of the "One Belt and One Road" strategy, the policy should be appropriately inclined to promote the development of Jingdezhen ceramic culture and creative industries, from system reform to service export, make clear a series of support policies, to promote the implementation of relevant supporting policies and ensure reasonable use of the cultural industry development fund. According to the distribution characteristics of existing ceramic cultural resources in Jingdezhen, we should do a good job in the spatial planning and gathering area layout of the creative industry park in the new period, encourage the mutual cooperation between enterprises to realize the benefits of industry collocation, and promote the formation and development of scale economies.

Improve the Support System Construction of Industrial Development. First of all, optimize the traditional talent structure and management model, establishment ceramic culture creative industry development talent support system in new era. Encourage Jiangxi colleges and continuing education and training institutions to create relevant professional, and in accordance with the actual needs of the market and industrial chain development, draw up plans for the cultivation of deep, high-level ceramic creative professionals. And select more excellent ones to do the depth of design 
or management training program, it is necessary to meet the needs of talent development at the moment, but also provide a broad space for its long-term development; Second, improve the industrial investment and financing system. Encourage enterprises and financial institutions to integrate into the ceramic culture and creative industries, relax the access conditions, provide preferential policies and support, reduce risks and enhance confidence and enthusiasm of investors; Finally, establish and improve the intellectual property protection system and market supervision mechanism, from subject cognition to objective supervision, jointly promoting the healthy development of Jingdezhen ceramic culture and creative industry.

\section{Conclusion}

To sum up, the "One Belt and One Road" strategy is a major reform and development opportunity, Jingdezhen ceramic cultural and creative industries must seize this rare opportunity, from the ideas, strategic layout, system construction, personnel training, intellectual property protection and sales platform construction, etc., to carry out the integration, uniting government, enterprises and university research institutions together to promote the new development of cultural and creative industry mechanism [5]. Focus on building ceramic culture and creative industries major project base, driving the development of historical and cultural Expo Park tourism and other aspects, to promote the further development of ceramic culture and creative industries in new era, make greater contributions to Jingdezhen social and economic progress.

\section{Acknowledgement}

Fund Project: Jiangxi Provincial Art Planning Project "'Study on the Development Strategy of Ceramic Cultural Creative Industry under the Strategy of "One Belt and One Road"' (YG2016225)

\section{References:}

[1] F. Chen. Technological innovation to promote the development of Jingdezhen ceramic culture and creative industry [D]. Jingdezhen Ceramic College, 2014.

[2] H. Zhu. Thinking on the improvement of Jingdezhen ceramic industry development and upgrading [J]. China Ceramics, 2015, (11): 1-4.

[3] Z.P. Wang. Jiangxi non-material cultural heritage protection and utilization and industrial development [D]. Nanchang University, 2013.

[4] F. Xiao. The change of consumption concept on the impact of ceramic industry under "One Belt and One Road" [J]. Art Technology, 2016, (06): $122+143$.

[5] Y.H. Zhang. Research on Jingdezhen ceramic industry and cultural tourism development in the background of "One Belt and One Road" [J]. Tourism Overview (the second half), 2017, (01): 189. 